\title{
ANALISIS VALUE ENGINEERING PADA PONDASI JEMBATAN (STUDI KASUS: PROYEK JEMBATAN KALI CENGGER TOL SEMARANG-SOLO RUAS SALATIGA- BOYOLALI SESI AMPEL-BOYOLALI)
}

\author{
1) Himawan Nur Aredha Putra, Prodi Teknik Sipil, Universitas Sebelas Maret \\ 2) Ir. Sugiyarto, M.T., Prodi Teknik Sipil, Universitas Sebelas Maret \\ 3) Ir. Ary Setyawan, M.Sc., Ph.D., Prodi Teknik Sipil, Universitas Sebelas Maret \\ Jl. Ir. Sutami 36A, Surakarta 57126; Telp. 0271-634524. Email: aredha.himawan@yahoo.com
}

\begin{abstract}
$V$ alue Engineering $(V E)$ is a creative and planned approach with the aim of identifying and streamlining unnecessary costs. The purpose of this study is to determine the components that can be organized with VE method, to know the best alternative that can replace the initial design, and to get a comparison of construction costs. The VE analysis was carried out at the Kali Cengger Jembatan Bridge Construction Project of Tol Semarang, Solo, Salatiga - Boyolali section of Ampel - Boyolali session.

In the VE study, there are 5 stages of value engineering job plan that need to do which are commonly known as the information stage, the creative or speculation stage, analysis stage, development stage, and the presentation and follow - up stage.

In this research, the job component which is chosen for VE study is the work of bridge foundation structure. The initial design of the initial foundation structure is bored pile $d=150 \mathrm{~cm}$ and the writer recommend two alternatives to replace the initial design. The first alternative is with bored pile foundation $d=100 \mathrm{~cm}$ with a depth of $8 \mathrm{~m}$ and the second alternative is with using pile foundation $d=100 \mathrm{~cm}$ with a depth of $10 \mathrm{~m}$. The cost of the foundation structure work with initial design is Rp. 70.741.519.932, 00 and after VE analysis is obtained an alternative cost $1 \mathrm{Rp}$. 70.472.541.358, 00, and alternative work cost 2 Rp. 69.406.435.961, 00 with savings of Rp. 1.335.083.971, 00.
\end{abstract}

Key words: value engineering, bridge, foundation, bored pile, pile.

\begin{abstract}
Abstrak
Rekayasa Nilai atau yang biasa dikenal dengan istilah V alue Engineering (VE) adalah suatu cara pendekatan kreatif dan terencana dengan tujuan untuk mengidentifikasi dan mengefisiensikan biaya-biaya yang tidak perlu. Tujuan dari penelitian ini adalah untuk mengetahui komponen yang dapat diefisiensikan dengan metode VE, mengetahui alternatif terbaik yang dapat mengganti desain awal, dan mendapatkan perbandingan biaya konstruksi. Analisis VE dilaksanakan pada Proyek Pembangunan Jembatan Kali Cengger Tol Semarang Solo ruas Salatiga Boyolali sesi Ampel-Boyolali.

Pada studi VE, ada 5 tahap yang harus dilakukan yang biasa dikenal dengan value engineering job plan yaitu tahap informasi, tahap kreatif atau tahap spekulasi, tahap analisis, tahap pengembangan, dan tahap penyajian dan tindak lanjut.

Dalam penelitian ini komponen pekerjaan yang dipilih untuk dilakukan studi VE adalah pekerjaan struktur pondasi jembatan. Desain awal struktur pondasi awal yaitu pondasi bored pile $\mathrm{d}=150 \mathrm{~cm}$ dan penulis merekomendasikan dua alternatif untuk menggantikan desain awal tersebut. Alternatif pertama dengan pondasi bored pile $\mathrm{d}=100 \mathrm{~cm}$ dengan kedalaman $8 \mathrm{~m}$ dan alternatif ke-dua menggunakan pondasi tiang pancang $\mathrm{d}=100 \mathrm{~cm}$ dengan kedalaman $10 \mathrm{~m}$. Biaya pekerjaan struktur pondasi dengan desain awal adalah Rp. 70.741.519.932,00 dan setelah dilakukan analisis VE diperoleh biaya alternatif 1 Rp. 70.472.541.358,00 dengan penghematan sebesar Rp. 268.978.574,00 dan biaya pekerjaan alternatif 2 Rp. 69.406.435.961,00 dengan penghematan sebesar Rp. 1.335.083.971,00.
\end{abstract}

Kata kunci: value engineering, jembatan, pondasi, bored pile, tiang pancang.

\section{PENDAHULUAN}

Rekayasa Nilai atau yang biasa dikenal dengan istilah V alue Engineering (VE) adalah suatu cara pendekatan kreatif dan terencana dengan tujuan untuk mengidentifikasi dan mengefisiensikan biaya-biaya yang tidak perlu. VE digunakan untuk mencari alternatif-alternatif atau ide-ide yang bertujuan untuk menghasilkan biaya yang paling baik/lebih rendah dari harga yang telah direncanakan sebelumnya tanpa mengurangi fungsi dasar dan kualitas pekerjaan.

VE dicetuskan oleh Lawrence Miles pada tahun 1940-an dan masuk ke Indonesia pada tahun 1986 melalui seminar dan workshop yang diberikan oleh DR. Suriana Chandra, CVS. VE telah banyak diterapkan di negara-negara maju di antaranya Amerika Serikat dan Jepang dan terbukti merupakan salah satu alat yang memegang peranan penting yang dapat dipakai untuk mencapai efisiensi dan membantu menghadapi krisis ekonomi dan inflasi.

Menurut Suriana Chandra (2014), pengaplikasian VE tidak hanya dilakukan pada saat tahap perencanaan. Ada kalanya perencanaan VE dilakukan pada tahap pelaksanaan maupun pada tahap akhir perencanaan karena situasi tertentu. Pada tahap perencanaan proyek Jembatan Kali Cengger belum diadakan VE dan analisis studi. 
Pengaplikasian VE pada penelitian ini dilakukan pada Proyek Pembangunan Jembatan Kali Cengger. Jembatan sepanjang $364 \mathrm{~m}$ ini berada di Kecamatan Ampel Kabupaten Boyolali dan merupakan salah satu bagian dari Proyek Pembangunan Jalan Tol Solo-Semarang Seksi IV (Salatiga-Boyolali). Pada umumnya, pekerjaan struktur memiliki biaya dan bobot pekerjaan yang cukup besar. Biaya tersebut dipengaruhi oleh pemilihan bahan dan desain yang digunakan. Pada studi kasus ini, VE dilakukan pada pekerjaan pondasi jembatan. Jembatan ini menggunakan bored pile dengan diameter $150 \mathrm{~cm}$ sebagai pondasi. Pekerjaan pondasi bored pile pada Jembatan Kali Cengger dirasa memiliki biaya yang cukup tinggi. Selain itu, pondasi bored pile memiliki kelemahan yaitu susah untuk mengontrol beton dan pada pemasangannya harus menyesuaikan dengan kondisi cuaca yang bisa memengaruhi waktu pelaksanaan proyek. Oleh karena itu, diperlukan alternatif lain untuk mengganti desain awal pondasi.

Dengan dilakukan aplikasi VE pada proyek jembatan tersebut, diharapkan bisa mengurangi biaya-biaya yang tidak diperlukan dan memunculkan alternatif-alternatif baru agar diperoleh biaya yang lebih rendah tanpa mengurangi performa dari bahan tersebut.

\section{LANDASAN TEORI \\ Dasar Teori \\ Value Engineering}

Usaha terorganisasi secara sistematis dan mengaplikasikan suatu teknik yang telah diakui, yaitu teknik, mengidentifikasi fungsi produk atau jasa yamg bertujuan memenuhi fungsi yang diperlukan dengan harga yang terendah (paling ekonomis). (Iman Soeharto, Manajemen Proyek dari Konseptual sampai Operasional, 2001). Suatu pendekatan yang kreatif dan terorganisir dengan tujuan untuk mengoptimalkan biaya dan atau kinerja sebuah sistem atau fasilitas. (Alphonse J. Dell Isola, Value Engineering in Construction Industry, 1975).

\section{Sejarah VE}

DR. Suriana Chandra CVS dalam bukunya Maximizing Construction Project and Invesment Budget Efficiency with Value Engineering (2014), menyatakan bahwa V alue engineering and analysis, value management terpikirikan pada perang dunia ke-2 sekitar tahun 1939-1945. Pada saat itu terjadi perusahaan General Electric sedang mengalami kesulitan akibat kebutuhan persenjataan yang semakin meningkat. Untuk menghadapi krisis tersebut, Lawrence Miles menemukan konsep VE dengan melakukan pendekatan fungsi yang bertujuan untuk mencari biaya yang ekonomis bagi suatu produk. Ternyata, setelah Miles menemukan dengan penggantian material yang digunakan ini, sering kali produk memberikan penampilan yang sama bahkan lebih baik, namun dengan biaya yang lebih rendah.

Ketika kontraktor dituntut untuk melakukan penghematan biaya tanpa mengurangi kualitas dan fungsi produk konstruksinya, para praktisi membentuk asosiasi pembelajaran di Washington, D.C. dengan nama' Society of American Value Engineering (SAVE)' pada tahun 1959 guna mempersatukan praktisioner dan mempromosikan pengembangan profesi. Pada tahun 1963, Departemen Pertahanan Amerika Serikat mulai mengaplikasikan VE untuk program konstruksi, dan merupakan agen konstruksi yang pertama memasukkan value engineering incentive clause pada setiap kontraknya.

\section{Jembatan}

Secara umum, pengertian jembatan adalah suatu struktur konstruksi yang berfungsi untuk menghubungkan dua bagian jalan yang terputus akibat beberapa kondisi seperti lembah yang dalam, alur sungai, danau, saluran irigasi, kali, jalan kereta api, jalan raya yang melintang tidak sebidang dan lain-lain.

\section{Pondasi}

Pondasi berfungsi untuk menerima beban dari bangunan bawah dan menyalurkannya ke tanah. Secara umum, pondasi dibedakan menjadi dua jenis, yaitu pondasi dangkal (shallow foundation) dan pondasi dalam (deep foundation). Pondasi dalam atau pondasi tak langsung juga dibedakan menjadi dua jenis, yaitu pondasi sumuran (caisson foundation) dan (pile foundation).

Dalam merencanakan sebuah pondasi, kita harus mengetahui jenis tanah di lokasi tersebut terlebih dahulu dengan cara pengujian tanah. Pengujian tersebut dapat dilakukan dengan alat Standard Penetration Test (SPT) atau Cone Penetration Test (CPT). Pada penelitian ini, pengujian dilakukan dengan menggunakan alat Standard Penetration Test (SPT). 


\section{Pondasi Bored Pile}

Pondasi bored pile merupakan jenis pondasi dalam yang memiliki bentuk seperti tabung memanjang yang terdiri dari campuran besi bertulang dengan beton dengan dimensi dan diameter tertetntu yang dipasang di dalam tanah. Pemasangan pondasi bored pile dilakukan dengan cara mengebor tanah terlebih dahulu kemudian diisi dengan besi tulangan yang telah dirangkai terlebih dahulu, kemudian dicor dengan beton.

\section{Daya Dukung Pondasi Bored Pile Kondisi SPT}

SPT adalah percobaan pengambilan sampel tanah pada kondisi tak terganggu (undisturbed soil). Metode yang digunakan unutk menentukan daya dukung pondasi adalah metode Meyerhoff (1976).

Persamaan yang digunakan dalam menentukan kapasitas dukung ujung tiang dan kapasitas geser selimut tiang untuk jenis tanah non kehesif adalah:

$\mathrm{Qp}=40 \times \mathrm{N}_{\text {SPT }} \times \mathrm{D} \times \mathrm{L} \times \mathrm{Ap}<400 \times \mathrm{N}_{\text {SPT }} \times \mathrm{Ap}$

Qs $=2 \times \mathrm{N}_{\text {SPT }} \times \mathrm{p} \times \mathrm{L}$

Kapasitas dukung izin tiang $(\mathrm{kN})$ menggunakan persamaan sebagai berikut:

$\mathrm{Q}_{\mathrm{izin}}=\frac{Q p+Q s}{S F}$

Untuk menentukan jumlah tiang, menggunakan persamaan berikut ini:

$$
\mathrm{n}=\frac{P u}{\text { Qizin }}
$$

Untuk menentukan efisiensi kelompok tiang, menggunakan persamaan berikut ini:

$$
\mathrm{Eg}=\frac{P u}{n \times \text { Qizin }}
$$

Kontrol kelompok tiang dihitung menggunakan persamaan berikut ini:

$\mathrm{SF}=\mathrm{n} \times \mathrm{Eg} \times \mathrm{Q}_{\text {izin }}>\mathrm{Pu}$

\section{Pondasi Tiang Pancang}

Pondasi tiang pancang (pile foundation) adalah bagian struktur yang digunakan untuk menerima dan menyalurkan beban struktur atas ke tanah penunjang yang terletak pada kedalaman tertentu.

\section{Daya Dukung Pondasi Tiang Pancang}

Pada jenis tanah kohesif, menurut Mayerhoff (1956) kapasitas dukung tiang pancang menggunakan beberapa persamaan, antara lain:

Dari data SPT, untuk menentukan kapasitas dukung tiang pancang menggunakan persamaan berikut ini:

$\mathrm{Qu}=40 \times \mathrm{Nb} \times \mathrm{Ap}<380 \times \mathrm{Nb} \times \mathrm{Ap}$

$\mathrm{Q}_{\text {izin }}=\mathrm{Qu} / \mathrm{SF}$

\section{METODE PENELITIAN}

Penelitian ini mengangkat disiplin ilmu manajemen konstruksi dengan menggunakan analisis Value Engineering Job Plan terhadap proyek pembangunan Jembatan Kali Cengger Tol Semarang-Solo. Metode merupakan langkah kerja yang memudahkan suatu pelaksanaan kegiatan dalam mencapai suatu tujuan tertentu. Metode penelitian dalam penyusunan skripsi ini meliputi metode pengumpulan data primer dan data sekunder, metode analisis dan prosedur penelitian. Data yang digunakan dalam penelitian ini yaitu Rencana Anggaran Biaya (RAB), gambar kerja, harga satuan pekerjaan, bahan, material dan tenaga kerja. Metode analisis yang digunakan pada penelitian ini adalah analisis Value Engineering Job Plan dengan lima tahapan yaitu tahap informasi, tahap kreatif, tahap analisis, tahap pengembangan dan tahap presentasi. 


\section{Tahap Informasi}

Tahap ini merupakan tahap awal studi VE yang bertujuan untuk memperoleh suatu pengertian secara menyeluruh terhadap sistem, struktur, atau bagian-bagian yang dilakukan studinya. Dalam menentukan sasaran studi, dilakukan analisis hukum pareto terhadap biaya proyek dan dilakukan pemahaman terhadap kriteria pembangunan apartemen sehingga diketahui pekerjaan yang akan dianalisis menggunakan VE.

\section{Tahap Spekulasi (Kreatif)}

Tahap spekulasi bertujuan untuk menghasilkan berbagai macam alternatif yang dapat memenuhi fungsi utama bangunan tersebut. Metode yang digunakan pada tahap ini adalah metode brainstorming. Brainstorming dimaksudkan untuk memecahkan berbagai masalah yang spesifik dengan mengutarakan dan mencatat gagasan-gagasan tanpa memikirkan sulit tidaknya ide tersebut untuk diimplementasikan. Alternatif tersebut dapat ditinjau dari berbagai aspek, diantaranya bahan atau material, metode pelaksanaan pekerjaan, maupun waktu pelaksanaan pekerjaan.

\section{Tahap Analisis}

Tahap analisis bertujuan untuk mengevalasi alternatif-alternatif yang telah didapatkan pada tahap kreatif. Pada tahap ini, alternatif yang telah diutarakan pada tahap sebelumnya dianalisis kemudian dilakukan pengambilan keputusan (judgement).

\section{Tahap Pengembangan}

Alternatif yang telah dipilih, dianalisis terhadap faktor teknis dan ekonomis agar dipersiapkan rekomendasi (saran) secara tertulis untuk diimplementasikan.

\section{Tahap Penyajian dan Tindak Lanjut}

Tujuan dari tahap ini adalah untuk meyakinkan para pengambil keputusan tentang apa yang telah dikembangkan. Tahap ini juga merupakan akhir dari Rencana Kerja Rekayasa Nilai (Value Engineering Job Plan). Isi dari tahap ini adalah perubahan desain yang diusulkan, perubahan waktu yang diusulkan, perubahan biaya dan total penghematan biaya yang akan diperoleh.

\section{HASIL DAN PEMBAHASAN}

\section{Tahap Informasi}

Dari hasil analisis Grafik Pareto dan Breakdown Cost Model pelaksanaan Proyek Jembatan Kali Cengger, pekerjaan yang memiliki bobot paling besar adalah pekerjaan struktur jembatan.

Tabel 1. Hasil Breakdown Cost Model

\begin{tabular}{cccccc}
\hline \multirow{2}{*}{ No } & \multirow{2}{*}{ Item Pekerjaan } & \multicolumn{2}{c}{ Biaya } & \multicolumn{2}{c}{ Kumulatif } \\
\cline { 3 - 6 } & & Rp. & $\%$ & Rp. & $\%$ \\
\hline 1 & Struktur & 70741519932 & 97.87648 & 70741519932 & 97.87648 \\
\hline 2 & Galian Struktur & 865380219.8 & 1.197322 & 71606900152 & 99.0738 \\
\hline 3 & Umum & 363675402.5 & 0.503174 & 71970575554 & 99.57697 \\
\hline 4 & Pekerjaan Tanah & 232829643.4 & 0.322138 & 72203405198 & 99.89911 \\
\hline 5 & Pembersihan Tempat Kerja & 72917913.6 & 0.100888 & 72276323111 & 100 \\
\hline & Jumlah & 72276323111 & 100 & 72276323111 & \\
\hline
\end{tabular}

Tabel di atas menjelaskan hasil Breakdown Cost Model pelaksanaan Proyek Jembatan Kali Cengger. Berdasarkan tabel di atas, pekerjaan yang memiliki bobot terbesar adalah pekerjaan struktur yang selanjutnya dianalisis menggunakan Hukum Distribusi Pareto. 


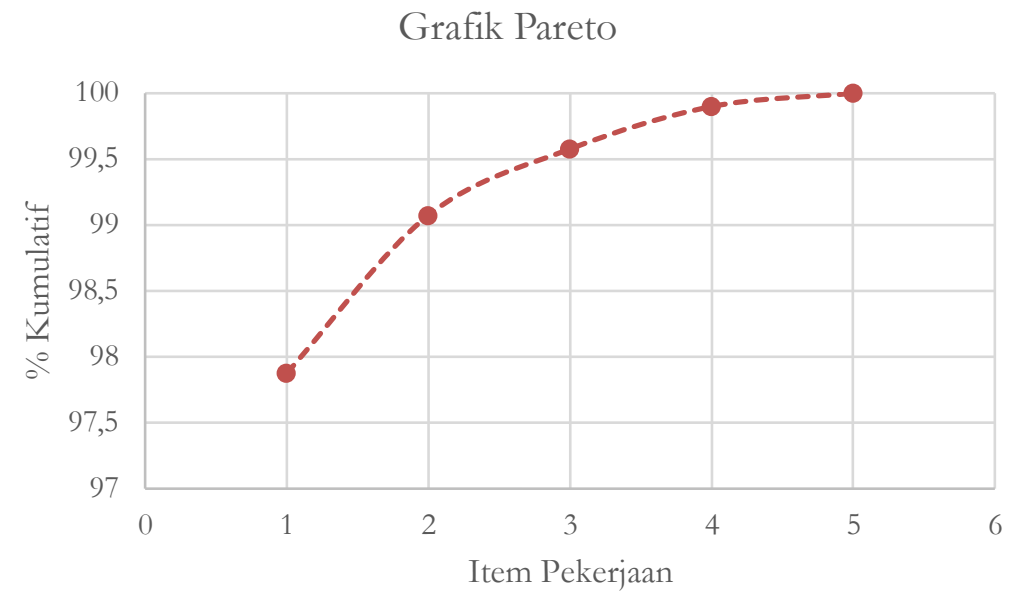

Gambar 1. Grafik Pareto

Gambar di atas menunjukkan hasil dari Analisis Pareto pelaksanaan Proyek Jembatan Kali Cengger. Berdasarkan Hukum Distribusi Pareto, maka pekerjaan yang layak untuk dilakukan analisis VE adalah pekerjaan struktur dengan bobot $97 \%$. Pada penelitian ini, pekerjaan yang akan dianalisis adalah struktur pondasi.

\section{Tahap Spekulasi (Kreatif)}

Tahap spekulasi adalah tahap yang dilakukan setelah mengetahui VE layak untuk dilanjutkan. Pekerjaan yang dilakukan pada tahap ini adalah menyediakan alternatif-alternatif untuk mengganti desain awal, antara lain:

a. Alternatif 1: Pondasi Tiang Bor (Bored Pile) diameter $100 \mathrm{~cm}$.

b. Alternatif 2: Pondasi Tiang Pancang Bulat Pretensioned diameter $100 \mathrm{~cm}$.

Dalam hal ini, yang menjadi pertimbangan dalam menentukan alternatif untuk pekerjaan pondasi Proyek Jembatan Kali Cengger adalah daya dukung pondasi tiang, metode pelaksanaan dan biaya.

\section{Tahap Analisis}

Tahap analisis bertujuan untuk mengevaluasi alternatif alternatif yang telah didapatkan pada tahap kreatif. Pada tahap ini, alternatif yang telah disampaikan pada tahap sebelumnya dianalisis kemudian dilakukan pengambilan keputusan. Hal yang ditinjau pada tahap ini adalah:

a. Biaya pada masing-masing alternatif

b. Analisis keuntungan dan kerugian

Tabel 2. Rekapitulasi Biaya Pekerjaan Pondasi

\begin{tabular}{cccccc}
\hline No & Uraian & Harga Satuan (Rp.) & Volume & Satuan & Jumlah Harga (Rp.) \\
\hline A & Pondasi Existing & & & & \\
\hline 1 & Pengadaan tiang & $7.501 .029,69$ & 468 & M1 & $3.510 .479 .700,00$ \\
\hline \multicolumn{2}{c}{ Jumlah Harga Pondasi Existing } & $7.501 .029,69$ & & & $3.510 .479 .700,00$ \\
\hline No & Uraian & Harga Satuan (Rp.) & Volume & Satuan & Jumlah Harga (Rp.) \\
\hline B & Alternatif 1 & & & \\
\hline 1 & Pengadaan tiang & $5.159 .009,27$ & 628,319 & M1 & $3.241 .501 .126,37$ \\
\hline \multicolumn{7}{c}{ Jumlah Harga Alternatif 1} & $5.159 .009,27$ & & & $3.241 .501 .126,37$ \\
\hline No & Uraian & Harga Satuan (Rp.) & Volume & Satuan & Jumlah Harga (Rp.) \\
\hline C & Alternatif 2 & & & & \\
\hline 1 & Penyediaan tiang & $2.116 .213,93$ & 785,398 & M1 & $1.662 .070 .532,09$ \\
\hline 2 & Pemancangan & $628.121,15$ & 785,398 & M1 & $493.325 .197,29$ \\
\hline 3 & Join Las & $200.000,00$ & 100 & Titik & $20.000 .000,00$ \\
\hline \multicolumn{7}{c}{ Jumlah Harga Alternatif 2 } & $2.944 .335,08$ & & & 2.175 .395 .729 \\
\hline
\end{tabular}


Tabel di atas menunjukan rekapitulasi hasil biaya pekerjaan pondasi dari pondasi existing, alternatif 1 dan alternatif 2. Berdasarkan tabel di atas, alternatif 2 memiliki biaya paling rendah.

Tabel 3. Keuntungan dan Kerugian Masing-masing Alternatif

\begin{tabular}{|c|c|c|}
\hline Alternatif & Keuntungan & Kerugian \\
\hline \multirow{6}{*}{$\begin{array}{l}\text { Desain } \\
\text { Awal }\end{array}$} & Harga cukup murah & Beton susah dikontrol \\
\hline & Proses pelaksanaan mudah & Memerlukan casing \\
\hline & Mudah menembus tanah & Pengeboran dan pengecoran tergantung cuaca \\
\hline & Tidak memerlukan penyambungan tiang & $\begin{array}{l}\text { Terkadang tiang pendukung kurang sempurna } \\
\text { karena ada lumpur tertimbun di dasar }\end{array}$ \\
\hline & Lebih ramah lingkungan & $\begin{array}{l}\text { Pemeriksaan kualitas hanya dapat dilakukan } \\
\text { secara tidak langsung }\end{array}$ \\
\hline & Mobilisasi lebih mudah & \\
\hline \multirow{6}{*}{$\begin{array}{l}\text { Alternatif } \\
\quad 1\end{array}$} & Harga cukup murah & Beton susah dikontrol \\
\hline & Proses pelaksanaan lebih mudah & Memerlukan casing \\
\hline & Mudah menembus tanah & Pengeboran dan pengecoran tergantung cuaca \\
\hline & Tidak memerlukan penyambungan tiang & $\begin{array}{l}\text { Terkadang tiang pendukung kurang sempurna } \\
\text { karena ada lumpur tertimbun di dasar }\end{array}$ \\
\hline & Lebih ramah lingkungan & $\begin{array}{l}\text { Pemeriksaan kualitas hanya dapat dilakukan } \\
\text { secara tidak langsung }\end{array}$ \\
\hline & Mobilisasi lebih mudah & \\
\hline \multirow{5}{*}{$\begin{array}{l}\text { Alternatif } \\
\quad 2\end{array}$} & Harga lebih murah & Perlu penyambungan tiang \\
\hline & Proses pelaksanaan lebih mudah & $\begin{array}{l}\text { Perlu penyediaan tempat yang cukup luas untuk } \\
\text { penampungan }\end{array}$ \\
\hline & Tidak masalah dengan muka air dangkal & Mobilisasi lebih susah \\
\hline & Mutu beton terjamin & $\begin{array}{l}\text { Proses pemancangan menimbulkan suara bi- } \\
\text { sing dan getaran }\end{array}$ \\
\hline & Daya dukung tidak hanya dari ujung tiang & \\
\hline
\end{tabular}

Berdasarkan tabel di atas, alternatif 2 memiliki risiko yang lebih rendah dibanding alternatif yang lain.

\section{Tahap Pengembangan}

Berdasarkan analisis yang telah dilakukan, maka penulis menyarankan untuk menggunakan tiang pancang sebagai pondasi jembatan karena memiliki biaya yang lebih rendah dari desain awal.

\section{Tahap Penyajian dan Tindak Lanjut}

Dalam penerapan metode VE, didapat dua alternatef yaitu alternatif 1 seluruh pondasi pada jembatan dilakukan reduksi diameter dari $\mathrm{D}=150 \mathrm{~cm}$ menjadi $\mathrm{D}=100 \mathrm{~cm}$, sedangkan alternatif 2 semua pondasi diganti dengan pondasi tiang pancang bulat pretensioned diameter $100 \mathrm{~cm}$. Perbandingan dari segi biaya dan daya dukung dapat dilihat pada tabel berikut.

Tabel 4. Rekapitulasi Hasil Akhir Penghematan Biaya

\begin{tabular}{cccccc}
\hline No & Alternatif & Biaya Existing (Rp.) & Biaya Alternatif (Rp.) & Selisih & $\%$ \\
\hline 1 & Alternatif 1 & 70.741 .519 .932 & 70.472 .541 .358 & 268.978 .574 & 0,38 \\
\hline 2 & Alternatif 2 & 70.741 .519 .932 & 69.406 .435 .961 & 1.335 .083 .971 & 1,88 \\
\hline
\end{tabular}

Tabel 4 menunjukkan hasil akhir penghematan biaya. Alternatif 2 memiliki selisih yang lebih besar yaitu 1,88\%.

Tabel 5. Rekapitulasi Daya Dukung Pondasi

\begin{tabular}{cccccc}
\hline No & Jenis Tiang & Diameter $(\mathrm{cm})$ & Jumlah Tiang & $\begin{array}{c}\text { Daya Dukung Izin } \\
\text { satu tiang }(\mathrm{kN})\end{array}$ & $\begin{array}{c}\text { Daya dukung ke- } \\
\text { lompok }(\mathrm{kN})\end{array}$ \\
\hline 1 & Pondasi existing & 150 & 96 & 150,9375 & 14490 \\
\hline 2 & Alternatif 1 & 100 & 100 & 175,30097 & 17530,097 \\
\hline
\end{tabular}


Tabel 5 menunjukkan rekapitulasi perhitungan daya dukung pondasi. Berdasarkan tabel di atas, alternatif 2 memiliki daya dukung yang lebih rendah tetapi masih memenuhi factor keamanan yang telah ditentukan.

\section{SIMPULAN}

Dalam penelitian ini komponen pekerjaan yang dipilih untuk dilakukan studi VE adalah pekerjaan struktur pondasi jembatan. Desain awal struktur pondasi awal yaitu pondasi bored pile $\mathrm{d}=150 \mathrm{~cm}$ dan penulis merekomendasikan dua alternatif untuk menggantikan desain awal tersebut. Alternatif pertama dengan pondasi bored pile $\mathrm{di}=100 \mathrm{~cm}$ dan alternatif ke-dua menggunakan pondasi tiang pancang $\mathrm{d}=100 \mathrm{~cm}$. Adapun alternatif terbaik yang dipilih oleh penulis sebagai pengganti desain awal adalah penggunaan tiang pancang $\mathrm{d}=100 \mathrm{~cm}$ sebagai pondasi jembatan karena memiliki biaya yang lebih rendah dari desain awal. Biaya pekerjaan struktur pondasi dengan desain awal adalah Rp. 70.741.519.932,00 dan setelah dilakukan analisis VE diperoleh biaya alternatif I Rp. 70.472.541.358,00 dengan penghematan sebesar Rp. 268.978.574,00 atau 0,38 \% dan biaya pekerjaan alternatif II Rp. 69.406.435.961,00 dengan penghematan sebesar Rp. 1.335.083.971,00 atau 1,88\%.

\section{REKOMENDASI}

1. Pada penelitian ini, penulis merekomendasikan menggunakan pondasi tiang pancang diameter $100 \mathrm{~cm}$ sebagai pengganti desain awal karena memiliki biaya yang lebih murah dan memiliki daya dukung yang masih memenuhi syarat.

2. Penerapan VE tidak hanya dapat dilakukan pada pekerjaan struktur (pekerjaan dengan presentase biaya besar), tetapi juga dapat dilakukan untuk pekerjaan lainnya yang memiliki potensi penghematan seperti arsitektur, mekanikal dan elektrikal serta plumbing.

3. Agar pelaksanaan studi VE lebih bervariasi maka dapat digunakan alternatif yang lebih banyak dan luas, mengingat saat ini muncul berbagai macam bahan yang lebih murah, mudah dan bermutu.

4. Untuk mendapatkan penghematan yang optimal, VE dapat dilibatkan pada setiap tahapan proyek, mulai dari tahap konsep, perencanaan dan pelaksanaan. Hal ini terutama dapat dilaksanakan pada proyek yang besar dengan jumlah item pekerjaan yang banyak.

5. Pada penelitian selanjutnya sebaiknya juga diteliti mengenai aplikasi VE untuk tenaga kerja dan waktu pelaksanaan proyek.

\section{UCAPAN TERIMAKASIH}

Ucapan terima kasih pertama ditujukan kepada Allah SWT atas limpahan rahmat dan nikmatnya. Selanjutnya kepada Ir. Sugiyarto, M.T. dan Ir. Ary Setyawan, M.Sc., Ph.D. selaku dosen pembimbing yang telah memberi arahan dan masukan dalam penelitian ini.

\section{REFERENSI}

Abrar Husen. 2011. Manajemen Proyek. Yogyakarta: Andi Offset.

Agus Iqbal Manu. 1995. Dasar-Dasar Perencanaan Jembatan Beton Bertulang. Dinas Pekerjaan Umum. 77

Bambang Supriyadi; \& Agus S Muntohar. 2007. Jembatan. Yogyakarta: Beta Offset.

Barrie, S, Donald; Paulson, C, Boyd; \& Sudinarto. 1995. Manajemen Konstruksi Propesional. Jakarta: Erlangga.

Bowles, E, Josep. 1991. Analisa dan Desain Pondasi. Jakarta: Erlangga.

Dell' Isola, J, Alphonse. 1975. Value engineering in the Construction Industry. New York: Van Nostrand Reinhold Company.

Djoko Wilopo. 2009. Metode Konstruksi dan Alat-alat Berat. Jakarta: Universitas Indonesia.

Ferdian, J. 2015. Penerapan V alue Engineering Pekerjaan Bangunan Bawah Jembatan pada Pekerjaan Pondasi Tiang Pancang (Studi Kasus : Penggandaan Jembatan Lamnyong Banda Aceh). Pascasarjana Universitas Syiah Kuala.

Hardiyatmo, H, C. 2002. Teknik Pondasi 2. Yogyakarta: Beta Offset.

Harmoko. 2016. Aplikasi Value Engineering pada Proyek Konstruksi (Studi Kasus: Proyek Pembangunan Jembatan Tebat Gheban Kota Pagar Alam). Universitas Muhammadiyah Yogyakarta

Hermawan, T, D. 2010. Aplikasi Value Engineering Pada Proyek Konstruksi (Studi Kasus : Proyek Pembangunan Gedung PBKP Yogyakarta). Universitas Muhammadiyah Yogyakarta.

H. Sabrang. 1998. Value Engineering, Universitas Atma Jaya Yogyakarta

Iman Soeharto. 2001. Manajemen Proyek dari Konseptual Sampai Operasional. Jakarta: Erlangga.

Irika Widiasanti; \& Lenggongeni. 2013. Manajemen Konstruksi. Bandung: Remaja Rosdakarya. 
Kurniawan, V, U. 2009. Penerapan Value Engineering Dalam Penyeleggaran Infrastruktur Bidang Ke-PU-an Di Lingungan Departemen Pekerjaan Umum Dalam Usaha Meningkatkan Efektivitas Penggunaan Anggaran. Universitas Indonesia.

Pricilia Girsang. 2009. Analisa Daya Dukung Pondasi Bored Pile Tunggal Pada Proyek Pembangunan Gedung Crystal Square JL. Imam Bonjol No.6 Medan. Universitas Sumatera Utara.

Puji Sri Lestari. 2011. Penerapan Value Engineering Untuk Efisiensi Biaya Pada Proyek Bangunan Gedung Berkonsep Green Building (Studi Kasus : Proyek Pembangunan Gedung Menteri). Universitas Indonesia.

Struyk, J, H; Van Der Veen; \& Soemargono. 1995. Jembatan. Jakarta: Pradnya Paramita.

Suriana Chandra. 2014. Maximizing Construction Project and Invesment Budget Effieciency with Value Engineering. Jakarta: PT Elex Media Komputindo 